\title{
Doce veneno: uma análise do consumo de bebidas açucaradas por adolescentes
}

\author{
Sweet poison: an analysis of adolescents" consumption of sugar- \\ sweetened beverages
}

Dulce veneno: un análisis del consumo de bebidas azucaradas por adolescentes

Thaína Rocha Balbino ${ }^{1, a}$

thainarochabalbino@hotmail.com | http://orcid.org/oooo-0002-3382-7472

Stephanie Ingrid Souza Barboza ${ }^{1, b}$

stephanieisb@gmail.com | http://orcid.org/o000-0002-2640-2070

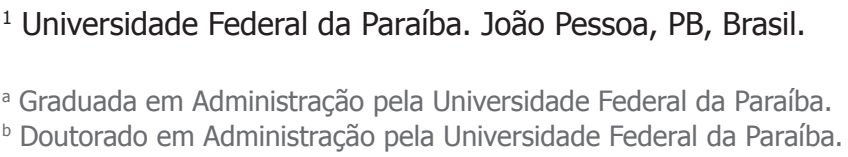

\section{Resumo}

O presente estudo visa compreender os fatores de influência para a redução do consumo das bebidas açucaradas. Nesse intuito, adotou-se uma abordagem qualitativa, a fim de desenvolver ferramentas de marketing social para a promoção da redução do consumo entre adolescentes. Foram realizadas entrevistas gravadas em áudio, com roteiro semiestruturado, sendo entrevistados onze adolescentes de 16 a 18 anos, variando entre estudantes do ensino médio de instituições públicas e privadas do estado da Paraíba. Os resultados indicaram que os principais incentivos para o consumo são o sabor, preço, praticidade e o assédio dos amigos e familiares que incentivavam o consumo de bebidas açucaradas. Fazendo o uso de ferramentas de marketing social, verificou-se que a conscientização sobre os aspectos negativos da ingestão dessas bebidas, a inserção de ações reguladoras e a exposição dos malefícios contribuem para uma nova consciência sobre o consumo dessas bebidas e a redução do consumo.

Palavras-chave: Marketing social; Bebidas açucaradas; Adolescentes; Saúde pública; Conscientização. 


\begin{abstract}
In order to understand the influence factors for the reduction of consumption of sugar-sweetened beverages, a qualitative approach was adopted in order to develop social marketing tools to promote consumption reduction among adolescents. Interviews were recorded, with a semi-structured script. Eleven adolescents aged 16 to 18 years were interviewed, varying among high school students from public and private institutions in the state of Paraíba. The results indicated that the main incentives for consumption are the taste, price, practicality and harassment of friends and family that encouraged the consumption of sugary drinks. Using social marketing tools, it was found that awareness of the negative aspects of the intake of these beverages, the insertion of regulatory actions and the exposure of the maladies contribute to a new awareness about the consumption of these beverages and the reduction of consumption.
\end{abstract}

Keywords: Social marketing; Sugars; Adolescents; Public health; Awareness.

\title{
Resumen
}

Con el objetivo de comprender los factores de influencia para la reducción del consumo de las bebidas azucaradas, se adoptó un abordaje cualitativo, con el fin de desarrollar herramientas de marketing social para la promoción de la reducción del consumo entre adolescentes. Se realizaron entrevistas grabadas por audio, con guión semiestructurado, siendo entrevistados once adolescentes de 16 a 18 años. Los resultados indicaron que los principales incentivos para el consumo son el sabor, precio, practicidad y el acoso de los amigos y familiares que incentivaban el consumo de bebidas azucaradas. $\mathrm{Al}$ hacer el uso de herramientas de marketing social, se verificó que la concientización sobre los aspectos negativos de la ingestión de esas bebidas, con la inserción de acciones reguladoras y la exposición de los maleficios contribuyen a una nueva conciencia sobre el consumo de esas bebidas y la reducción del consumo.

Palabras clave: Marketing social; Bebidas azucaradas; Adolescentes; Salud pública; Consciencia.

\section{Contribuição dos autores:}

Concepção e desenho do estudo: Stephanie I S Barboza.

Análise ou interpretação dos dados: Thaína R Balbino.

Redação do manuscrito: Thaína R Balbino e Stephanie I S Barboza.

Revisão crítica do conteúdo intelectual: Stephanie I S Barboza.

Declaração de conflito de interesses: não há.

Fontes de financiamento: não há.

Considerações éticas: não há.

Agradecimentos/Contribuições adicionais: não há.

Histórico do artigo: submetido: 07 fev. 2018 | aceito: 27 maio. 2019 | publicado: 28 jun. 2019.

Apresentação anterior: $10^{\circ}$ Congresso Latino-americano de Varejo, 2017.

Licença CC BY-NC atribuição não comercial. Com essa licença é permitido acessar, baixar (download), copiar, imprimir, compartilhar, reutilizar e distribuir os artigos, desde que para uso não comercial e com a citação da conferindo os devidos créditos de autoria e menção à Reciis. Nesses casos, nenhuma permissão é necessária por parte dos autores ou dos editores. 


\section{Introdução}

O marketing social pode ser colocado como ferramenta de apoio para a evolução social, conscientizando os indivíduos acerca das consequências de suas atitudes e proporcionando a disseminação de comportamentos que enfrentam as adversidades impostas pelo mercado e que geram externalidades negativas para os consumidores e a sociedade como um todo ${ }^{1-4}$. Dessa forma, seu principal interesse é maximizar o bem-estar social, proporcionando a conscientização dos indivíduos e impulsionando mudanças no consumo.

Verifica-se que as práticas de marketing das empresas alimentícias são eficazes na promoção de seus produtos, principalmente quando se trata de bebidas açucaradas, estimulando os consumidores mais jovens com o foco na manutenção desse consumo ${ }^{5}$. Assim, o marketing social pode ser elencado como referência de ação contra esse tipo de problema na sociedade, pois é um campo eficaz para a promoção da mudança de comportamento do indivíduo e pode contribuir para a redução do consumo de bebidas açucaradas por meio da conscientização e da reeducação alimentar, além de minimizar os custos relacionados às diversas doenças crônicas não transmissíveis ${ }^{6,7}$.

Partindo desse entendimento, os hábitos de consumo de alimentos são decorrentes de aspectos culturais, antropológicos, socioeconômicos epsicológicos do ambiente social, eatualmente se caracterizam pela necessidade de produtos que sejam de rápido preparo ${ }^{8,9}$. Nesse contexto, emergem as bebidas açucaradas que podem ser exemplificadas pelos refrigerantes, sucos artificiais, bebidas à base de soja e bebidas lácteas (achocolatados) ${ }^{10}$.

A adolescência é o estágio da vida onde os hábitos adquiridos podem permanecer até a vida adulta. Os jovens de maneira geral tendem a ter maior preferência por alimentos com alto teor de gordura saturada, sódio e carboidratos refinados, os quais podem ser encontrados em alimentos de fácil preparo, como é o caso de alimentos industrializados e das bebidas com adição de açúcar¹.

No caso das bebidas açucaradas, crianças e adolescentes são mais expostos, e tais bebidas aumentam consideravelmente o risco de obesidade e diabetes tipo 1, uma vez que a ingestão de uma bebida com 8 colheres de açúcar por dia aumenta em 60\% a probabilidade de uma criança se tornar obesa. Sucos de frutas comercializados no Brasil oferecem em sua embalagem os valores nutricionais de uma porção de 200ml, sendo possível verificar que há a presença de cerca de $29 \mathrm{~g}$ de açúcar, equivalendo a cerca de 2 colheres de açúcar em apenas 1 copo de 20oml. Assim, consumindo 1 copo por dia durante uma semana, seriam ingeridos por volta de $145 \mathrm{~g}$ de açúcar ${ }^{2,3,5,6}$.

O consumo excessivo de açúcar na dieta pode afetar diretamente o desenvolvimento do aprendizado e a memória, sendo um problema na adolescência, quando o corpo está em crescimento e criando hábitos. Quanto menos uma criança consumir bebidas açucaradas, menos seu paladar vai se adaptar a elas e menor será a chance de se criar o hábito quando adulto. As pesquisas apontaram que o consumo desse produto é influenciado fortemente pelo sabor, seguido do estímulo do consumo pelos pais. Observou-se ainda que a bebida mais consumida nas refeições é o suco de fruta industrializado (38\%), seguido do refrigerante (29\%) ${ }^{11,12}$.

E quando se considera o consumo desenfreado de bebidas açucaradas, verifica-se um papel de destaque no desenvolvimento de doenças crônicas não transmissíveis (DCNT) - aquelas desenvolvidas no decorrer da vida e de longa duração (por exemplo: problemas cardiovasculares, câncer, diabetes e as doenças respiratórias crônicas) - sendo considerado um dos grandes problemas de saúde pública e atingindo cerca de $60 \%$ de mortes no mundo ${ }^{13,14}$. Existe clara associação entre o consumo de alimentos de baixo valor nutricional e os custos financeiros de hospitalizações e medicamentos para o controle dos problemas de saúde relacionados ${ }^{15-17}$.

Entre os 20 alimentos mais consumidos no Brasil por adolescentes, o refrigerante aparece em $6^{\circ}$ lugar, muito à frente de frutas e hortaliças. Segundo o IBGE (2014), 23,4\% das pessoas com 18 anos ou mais consomem refrigerantes por pelo menos cinco dias na semana. Considerando-se a adoção de uma dieta não balanceada, como costuma ser a dos adolescentes, o baixo consumo de frutas e o alto consumo de alimentos 
industrializados, é fácil achar a justificativa para que 17,1\% dos adolescentes de 12 a 17 anos estejam com sobrepeso, enquanto $8,4 \%$ sejam avaliados como obesos ${ }^{18,19}$.

A Organização Mundial da Saúde (OMS) apresentou novas diretrizes em 2014 que atualizaram os valores recomendados de ingestão de açúcar, indicando apenas $5 \%$ do total de calorias ingeridas por dia oriundas do açúcar7. Apesar de todos os apelos que as organizações da saúde têm feito a respeito da redução do consumo dessas bebidas industrializadas e do desenvolvimento de mercados que comercializam alimentos saudáveis, os brasileiros comem mal e ingerem grandes quantidades de produtos industrializados. É evidente que o consumo das bebidas açucaradas não é apenas influenciado por campanhas publicitárias de grandes empresas, mas também apoiado pelos pais e responsáveis desses jovens, já que a maioria dos adolescentes consome bebidas açucaradas em suas próprias casas ${ }^{16}$.

\section{Elementos caracterizadores do consumo de bebidas açucaradas por jovens}

Diversos são os estudos que caracterizam o consumo de bebidas açucaradas, já que são vistos como um dos principais alimentos que contribuem para o desenvolvimento da obesidade em crianças e adolescentes. Flora e Polenick ${ }^{20}$ expuseram que a redução desse consumo pode contribuir para a melhora do desempenho atlético, acadêmico e cognitivo.

Nos Estados Unidos, 1 a cada 6 crianças é obesa. A obesidade está relacionada com a falta de equilíbrio nutricional, a falta de acesso e disponibilidade de alimentos saudáveis que são fatores relacionados ao ambiente em que o adolescente está inserido ${ }^{21,22}$. Nesse sentido, estudos apresentaram que os maiores consumidores de bebidas açucaradas são do sexo masculino, obesos e costumam fazer várias refeições fora de casa, evidenciando que a rotina alimentar dos adolescentes interfere na frequência de consumo de bebidas açucaradas ${ }^{23,24}$.

Com isso, é possível verificar que o comportamento alimentar é influenciado por uma complexa interação de fatores individuais e ambientais ${ }^{25}$. No que diz respeito aos aspectos que possam contribuir para a mudança de comportamento alimentar, Bleakley e colaboradore ${ }^{26}$ realizaram um experimento a fim de verificar se o consumo excessivo de bebidas açucaradas poderia ser regulado com intervenção por meio da exposição das informações calóricas das bebidas açucaradas, possibilitando aos adolescentes maior acesso à informação. Foi verificado que depois da intervenção houve uma redução tanto da compra de bebidas de imediato como da probabilidade de adquiri-las posteriormente.

Bleakley e outros autores ${ }^{26}$ ainda ressaltam que a propagação de ideias que contribuam diretamente para a aquisição de novos hábitos ocorre de forma mais acentuada por meio de campanhas que se baseiam em apelos emocionais como humor, medo e carinho, já que tais apelos afetam os correlatos cognitivos e emocionais de adolescentes. No processo de análise dos elementos que influenciam o comportamento alimentar desse grupo, Verstraeten et al. ${ }^{25}$ verificaram a dificuldade de acesso à alimentação saudável no âmbito dos fatores ambientais como sendo um provável influenciador do consumo de bebidas açucaradas. Além das questões relacionadas ao ambiente social, que dizem respeito ao nível de permissibilidade que os pais, responsáveis e as pessoas envolvidas no ambiente escolar desempenham diante do consumo de bebidas açucaradas por adolescentes, ainda foram identificados aspectos relacionados à conveniência do consumo.

A respeito dos fatores de influência para o consumo de bebidas açucaradas, Pettigrew et al. ${ }^{27}$ ainda verificou a pressão social em que os adolescentes são impulsionados a consumir bebidas açucaradas para serem aceitos em determinados grupos e situações. Grimm et al. ${ }^{28}$ expõem que os aspectos relacionados a atratividade do produto se relacionam fortemente com o sabor das bebidas açucaradas ${ }^{27,28}$. Decorrente desse levantamento é possível afirmar que as ações de marketing social para a redução do consumo de bebidas açucaradas devem atuar nas preferências de consumo que são desenvolvidas na fase inicial da vida, no intuito de promover a conscientização do consumo e da necessidade de controle do consumo alimentar em uma fase precoce ${ }^{27,28}$. 
Diversos estudos no marketing são voltados à área de saúde pública como forma de analisar novas posturas da sociedade, visto que muitos comportamentos de consumo podem ser prejudiciais para o bem-estar dos indivíduos ${ }^{29-32}$. Sob essa ótica, a discussão sobre questões alimentares se torna proeminente, dado que a OMS reconhece o consumo de bebidas açucaradas como sendo uma das causas da epidemia da obesidade.

Há comprovação da relação do consumo de refrigerantes com o aumento de gordura corporal - o índice de massa corporal (IMC). Há, também, uma associação direta do consumo desses produtos com padrões alimentares mais pobres em termos nutritivos, como por exemplo: a ingestão de salgadinhos, doces e outros alimentos processados ${ }^{21,33}$.

Por sua vez, são relevantes os efeitos do marketing das empresas de alimentação no comportamento de saúde pública e na escolha alimentar das crianças. Conforme relatos da Food Standards Agency (FSA), os resultados dessa pesquisa indicam que a promoção de alimentos tem um efeito negativo sobre as crianças, estimulando-os a consumir inconscientemente alimentos que podem ser nocivos à sua saúde ${ }^{32,34,35}$. Com efeito, é na infância e adolescência que muitos desses alimentos são inseridos, constituindo base para a formação de hábitos alimentares que podem permancer durante toda a vida.

A adolescência se destaca como uma época da vida em que os sujeitos se tornam mais sucetíveis aos apelos dos grupos sociais em que se inserem ou mesmo à mudança de estilo de vida. Além disso, questões relativas ao desenvolvimento econômico e social da região em que os adolescentes residem impactam significativamente na relação que a família tem com os hábitos alimentares ${ }^{36}$.

Com o objetivo de analisar o consumo de bebidas açucaradas por adolescentes na região Nordeste, foram considerados os principais fatores que implicam no consumo de bebidas açucaradas: a rotina alimentar $^{23,24}$, os apelos emocionais ${ }^{26}$, a acessibilidade, a permissividade, a conveniência ${ }^{25}$, a pressão social ${ }^{27}$ e a atratividade do produto ${ }^{28}$.

Torna-se relevante contribuir para a redução do consumo de bebidas açucaradas, ao passo em que o marketing social associa o conhecimento científico às tecnologias de marketing para a formação de propostas para novas posturas ou práticas de consumo, nesse caso, o consumo de alimentos prejudiciais à saúde com o intuito de mudança de comportamento da sociedade ${ }^{31,37}$.

Sendo assim, a proposta desse estudo é inovadora ao analisar as influências no consumo de bebidas açucaradas por adolescentes na região Nordeste, de forma a contribuir para campanhas que reduzam o consumo de bebidas açucaradas e influenciem a adoção de hábitos alimentares mais saudáveis. Para tanto, inicialmente é apresentada a discussão teórica sobre marketing social e o consumo de bebidas por adolescentes, para então desenvolver os procedimentos metodológicos, e, por fim, expor os resultados e discuti-los à luz do marketing social.

\section{Método}

Este tópico tem por objetivo descrever os procedimentos metodológicos que foram utilizados na investigação da questão: 'Como os adolescentes são influenciados para o consumo das bebidas açucaradas?', conferindo a esta pesquisa um caráter exploratório de abordagem qualitativa, fundamentada na experiência e escolhas de consumo dos indivíduos para promover a eficiência da redução do consumo de bebidas açucaradas por meio das ferramentas de marketing social.

Nesta pesquisa foi empregada como método de coleta de dados a entrevista, seguindo um roteiro semiestruturado (Quadro 1) com as dimensões definidas na revisão de literatura: hábitos alimentares; aspectos relacionados ao consumo de bebidas açucaradas; influências da família, escola e amigos no consumo alimentar; visão sobre alimentação saudável; atratividade do produto: sabor e conveniência ${ }^{38}$. No decorrer das entrevistas, percebeu-se a necessidade de adequação do roteiro para impulsionar os entrevistados a discorrerem sobre os temas em questão, já que a timidez, em alguns casos, prevaleceu. 
Quadro 1 - Roteiro Semiestruturado

\begin{tabular}{|c|c|}
\hline Tema & Perguntas \\
\hline Hábitos alimentares & $\begin{array}{l}1 \text { - Descreva sua rotina alimentar; } \\
2 \text { - Suponha que você queira comer de forma saudável: } \\
\text { a. O que você entende por alimentação saudável? } \\
\text { b. Na sua casa é difícil encontrar alimentos saudáveis? } \\
\text { c. Na sua escola é difícil encontrar alimentos saudáveis? }\end{array}$ \\
\hline $\begin{array}{l}\text { Aspectos relacionados ao consumo de } \\
\text { bebidas açucaradas }\end{array}$ & $\begin{array}{l}1 \text { - Qual o tipo de bebida açucarada que você mais gosta? } \\
2 \text { - Qual a bebida açucarada que você mais consome? }\end{array}$ \\
\hline $\begin{array}{l}\text { Influências da família, escola, amigos no } \\
\text { consumo alimentar }\end{array}$ & $\begin{array}{l}1 \text { - Na rotina alimentar da sua casa, com qual frequência há } \\
\text { algum tipo de bebida açucarada durante as refeições? } \\
2 \text { - Qual a opinião dos seus pais sobre o consumo de bebidas } \\
\text { açucaradas? } \\
3 \text { - Você já foi incentivado por alguém a não consumir este tipo } \\
\text { de alimento? } \\
4 \text { - Você faz escolhas alimentares diferentes de acordo com quem } \\
\text { está acompanhando você nas refeições (família ou amigos)? }\end{array}$ \\
\hline Visão sobre alimentação saudável & $\begin{array}{l}1 \text { - Você tem consciência da composição dos alimentos que você } \\
\text { consome? } \\
2 \text { - Você costuma olhar as informações nutricionais dos alimentos? } \\
3 \text { - Você se preocupa com seu peso? } \\
4 \text { - Você acha que o consumo dessas bebidas influencia no ganho } \\
\text { de peso? Qual sua visão sobre isso? }\end{array}$ \\
\hline $\begin{array}{l}\text { Atratividade do produto: sabor e } \\
\text { conveniência }\end{array}$ & $\begin{array}{l}1 \text { - Como você analisa a necessidade de consumir bebidas } \\
\text { açucaradas? } \\
2 \text { - Quais os principais motivos que te levam a consumir bebidas } \\
\text { açucaradas? } \\
3 \text { - Entre alguma bebida açucarada e outra bebida, mais saudável, } \\
\text { o sabor te influencia na escolha? }\end{array}$ \\
\hline
\end{tabular}

Fonte: As autoras (2017).

Participaram dessa pesquisa onze adolescentes entre 16 e 18 anos, sendo 4 do sexo masculino e 7 do sexo feminino, variando entre estudantes de ensino médio de instituições públicas e privadas do estado da Paraíba. Todas as entrevistas foram gravadas em áudio e posteriormente transcritas. As entrevistas tiveram uma duração de 8 a 20 minutos, e as transcrições foram de 3 a 4 laudas cada, no total de 36 laudas de transcrição, com espaçamento simples, fonte Arial e tamanho 11. A entrevista mais curta teve 8 minutos e 58 segundos com 3 laudas de transcrição, e a mais longa durou 19 minutos e 54 segundos resultando em 4 laudas de transcrição. Vale salientar que as entrevistas de curta duração ocorreram assim por timidez por parte dos entrevistados que nunca haviam passado pelo processo, mas isso não impactou a coleta tendo em vista que houve saturação argumentativa nos discursos dos entrevistados.

Os dados adquiridos por meio das entrevistas passaram por análise de conteúdo, uma vez que a proposta reside na comparação e na relação entre o discurso dos sujeitos de pesquisa e o consumo de bebidas açucaradas. O processo de análise de conteúdo se iniciou com as entrevistas. Posteriormente foi feita a transcrição e a leitura, com o interesse de compreender os aspectos expostos e, na sequência, evoluindo para a identificação e categorização dos dados coletados ${ }^{39}$. 


\section{Análise dos resultados}

Este item expõe as discussões decorrentes das análises das entrevistas expondo os resultados conforme emergiram as subcategorias da análise de conteúdo.

\section{Cotidiano alimentar}

A primeira seção da entrevista aborda os hábitos alimentares dos adolescentes e suas escolhas particulares de consumo alimentar.

\section{Como eu como?}

Durante a infância, são criados hábitos alimentares e de atividade física ${ }^{40}$, e é nessa fase que os familiares e responsáveis estão mais atentos às escolhas alimentares. Por outro lado, a descrição das práticas alimentares na adolescência tem se relacionado com dietas ricas em gorduras, açúcares e sódio com pequena participação de frutas e hortaliças ${ }^{41}$.

Na presente pesquisa, leva-se em consideração que os entrevistados moram no interior do estado da Paraíba e recebem influência da região sobre suas refeições, tais como: alimentação em família com horários definidos e a figura da mãe dona de casa que prepara comidas consideradas saudáveis por eles. Os dois entrevistados expostos abaixo mostram seus hábitos alimentares dentro de suas casas, com suas famílias e a mãe com o papel de principal motivadora de uma alimentação saudável.

"Sempre costumo comer bem no café da manhã como sempre queijos e ovos. No almoço sempre feijão, arroz, acompanhado de carne e salada. Nas refeições na minha casa sempre tem suco natural". (EIX).

“...No almoço, comida normal: arroz, feijão, carne com suco, não gosto de refrigerante ou kisuco (suco industrializado em pó)... De tarde eu tomo café com bolachas e na janta sempre tem alguma coisa tipo: macaxeira, inhame, arroz, carne com café”. (EXI).

A maioria dos entrevistados está em fase escolar e ainda mora com os familiares, o que contribui positivamente quando comparado àqueles que não vivem mais com os familiares, como é o caso dos jovens que já estão na universidade morando longe de casa ou cujos pais apresentam dificuldade de conciliar as refeições.

"Eu não tenho uma boa rotina alimentar, costumo pular algumas refeições e não faço refeições equilibradas, por morar longe de casa eu tenho que cozinhar, não é como era na minha casa, que minha mãe cozinhava... e assim eu acabo ficando sempre com preguiça e não comendo direito". (EVIII).

"De manhã eu não tomo café, só lancho no colégio no caso é pizza, coxinha, empadinha". (EIV).

Ao serem convidados a refletir sobre a sua alimentação, alguns dos jovens demonstraram falta de interesse em entender o que constituiria uma alimentação adequada ou mesmo aceitar uma alimentação mais saudável. Muitos relataram que, embora exista uma consciência sobre o que se caracteriza como uma boa alimentação, a atitude de se preocupar ou de aderir a hábitos alimentares mais saudáveis é tida como algo a se pensar posteriormente, como um reflexo de uma preocupação de pessoas mais velhas e doentes.

"Sei o que é ruim e o que é bom, mas hoje, costumo não me importar tanto assim". (EVIII). "Acredito que se alimentar de forma saudável não se trata de restrição alimentar e sim de qualidade de vida. Optar por alimentos naturais é de certa forma gratificante já que é possível observar como seu corpo reage bem aos mesmos”. (EX). 
A entrevistada VII evidenciou uma nova consciência em suas falas durante a entrevista. Relatou que, poucos meses antes, havia decidido perder peso e procurado profissionais da área de saúde. Em seu discurso, há a explicação sobre o que aconteceu quando eliminou o consumo de bebidas açucaradas em sua dieta.

"Uma alimentação balanceada com verduras, vegetais, frutas... Menos alimentos industrializados, menos sódio e gorduras... Antes de procurar uma nutricionista eu me alimentava muito mal, depois que resolvi perder peso foi que entendi como me alimentava mal... com todas as mudanças positivas eu me sinto melhor, vivo melhor e durmo melhor. (EVII).

A entrevistada ainda relata que a crescente independência e o início de uma vida social e profissional contribuíram para o hábito de comer rapidamente. Nessa fase também se iniciou a compra e o preparo dos seus próprios alimentos.

“...Não me alimento da forma que realmente gostaria, devido a correria diária, mas tento manter a minha feira bem saudável”. (EX).

Sendo assim, é possível entender que a manutenção dos hábitos alimentares da infância depende da presença dos familiares na vida dos adolescentes, uma vez que quando há o distanciamento familiar, muitos deles buscam por alimentos saborosos e práticos de ser preparados e facilmente adaptáveis à nova rotina de vida.

\section{Não como porque não encontro}

Ainda no contexto de discussão dos hábitos alimentares, os sujeitos foram questionados sobre a quantidade de alimentos saudáveis em suas casas. Quando morando com os familiares, a maioria evidenciou que há disponibilidade; mesmo que não desejem consumir, conseguem ter fácil acesso morando com os pais.

\footnotetext{
"Aqui em casa sempre tem alimentos saudáveis, é raro ter comida industrializada tipo: miojo ou comida pronta... essas coisas". (EXI).

“... encontro facilmente frutas e legumes. Assim como uma dieta equilibrada, sem exageros nos carboidratos e nem nas proteínas”. (EIX).
}

Para tanto, os entrevistados observaram que o fato de morar sozinho evidenciou as dificuldades de ter uma alimentação equilibrada e saudável distante do apoio dos pais.

"Na casa dos meus pais, todo dia tem salada, frutas, coisas mais naturais... Já no meu apartamento, nem sempre tem. Às vezes eu acho mais caro e mais trabalhoso de fazer, as coisas naturais sempre se estragam mais rápido...” (EVIII).

Quando questionados sobre a alimentação no ambiente escolar, os entrevistados de Ensino Médio relataram situações problemáticas em relação ao acesso a alimentos saudáveis na escola.

"Há uma diversidade de frituras e é raridade encontrar algo natural. O preço é exorbitante comparado às frituras". (EX).

“...praticamente não tem alimentos saudáveis, porque é sempre coxinha... frituras, sabe? E ‘kisuco', refrigerante”. (EVIII).

O Projeto de Lei PL 1755/2007 dispõe sobre a proibição da venda de refrigerantes em escolas de educação básica públicas ou particulares no Brasil. Essa lei já está em vigor e todos os entrevistados quando questionados sobre a venda de refrigerantes em suas escolas, afirmaram que não havia venda oficial. Entretanto, a lei não fez com que as escolas tornassem suas cantinas mais saudáveis, apenas eliminou a venda de um produto específico: refrigerante. Em consequência disso, houve uma adaptação mercadológica que permite os adolescentes comprarem as bebidas no comércio informal localizado nos arredores das instituições de ensino. 


\section{É doce!}

A segunda categoria abordou aspectos relacionados ao consumo de bebidas açucaradas, emergindo o sabor como principal condicionante de consumo. Na análise das escolhas sobre bebidas açucaradas, sete entre os onze entrevistados assumiram gostar e consumir mais refrigerante do que outros tipos de bebidas, como as lácteas e sucos prontos.

"Só tomo suco natural quando eu tô na casa dos meus pais, morando só eu não tenho liquidificador em casa, aí fica complicado fazer um suco. (...) todo dia tem kisuco, eu sempre compro na feira... de monte! Ou se não é refrigerante”. (EVIII).

"Eu gostava muito de refrigerante, toddynho e Ades. Todo dia no almoço era sempre CocaCola ou um Suco Ades de pêssego, e duas ou três vezes era fácil me ver tomando toddynho. Já teve dia de acordar e tomar 2 toddynhos com coxinha e isso de 7 h da manhã...” (EVII).

Como visto, o sabor e a conveniência são os fatores principais que fazem com que os indivíduos realizem suas escolhas alimentares, independentemente da situação econômica, tais características se mostram inegociáveis no momento da decisão de compra. Quando solicitados, os adolescentes preferem o que é mais saboroso ao paladar e fácil de preparar do que as opções naturais ${ }^{16}$.

\section{Se todo mundo pode, eu também!}

Há diversas influências para o consumo de bebidas açucaradas por adolescentes, aspectos como sabor, acessibilidade e consumo pelos pais, que são modelo para os jovens ${ }^{16}$. $\mathrm{Na}$ análise foi possível identificar que a maioria dos pais não aprovavam o consumo das bebidas açucaradas, entretanto, não tomavam medidas para reduzi-lo. Um dos entrevistados relata como foram os cuidados e recomendações dos pais com sua alimentação.

\footnotetext{
"Meus pais sempre mandaram tomar cuidado com meu peso, mas nunca deixaram de trazer para casa esse tipo de bebida. Nunca falaram exatamente 'para de tomar refrigerante, isso vai te ajudar a emagrecer'. Eles apenas me mandavam tomar cuidado e só, sempre falei para eles que não adiantou muita coisa, quando eu era mais nova, falar que eu não deveria tomar e continuar colocando em casa, eu abro a geladeira e tem lá: refrigerante, toddynho, Ades..." (EVII).
}

A entrevistada VII evidenciou seus esforços para perder peso, contou que havia procurado ajuda médica há alguns meses. A obesidade tem sido reconhecida como uma doença e uma questão de saúde pública, sendo verificado durante a entrevista VII que apesar dos seus esforços pessoais, o que mais prejudicava o processo de perda de peso era a influência dos seus familiares e amigos.

Em certa medida, alguns pais até se mostram conscientes, atuando em prol da redução do consumo.

"Minha mãe fala frequentemente que não faz bem à saúde consumir bebidas açucaradas e, por isso, raramente tem na minha casa. Já meu pai é indiferente sobre isso, ele costuma estimular o consumo de sucos naturais, mas não proíbe ou fala que não deve tomar..." (EIX).

Os papéis paternais variam ao longo do tempo e da cultura em que os indivíduos estão inseridos, sendo possível observar que poucas vezes o pai exerce a função de cuidar dos filhos, enquanto a mãe assume a responsabilidade pelo desenvolvimento da criança. Em algumas culturas, cabe ao pai a compra dos alimentos e à mãe o papel de prepará-los dentro de casa ${ }^{42}$. A maioria dos entrevistados evidenciou que suas mães assumiam o papel de cozinhar os alimentos e regrar os hábitos alimentares da casa:

\footnotetext{
“...às vezes minha mãe faz panquecas" (EI);

"não é como era na minha casa, que minha mãe cozinhava" (EVIII).
} 
Sendo assim, observa-se que os bons hábitos alimentares partem da contribuição direta do papel da mãe na família.

Complementarmente, a situação de saúde se tornou o principal elemento desencadeador das mudanças do hábito alimentar nos lares. Como o sujeito relata, foi preciso perceber o aumento de peso e as alterações na saúde familiar para que alguma restrição alimentar lhes fosse imposta.

\begin{abstract}
"Antes aqui em casa a gente tomava muito refrigerante. Com o tempo a gente foi percebendo que estávamos engordando e ficando mal. Então meus pais decidiram cortar refrigerante e esse tipo de comida industrializada. Pararam de comprar, começaram a obrigar a gente a não comer fora essas coisas também. Antes, meus exames de sangue eram sempre alterados, as taxas lá em cima, fora do normal. (...) depois da mudança, de parar de comprar, meus exames ficaram normais.” (EXI).
\end{abstract}

De fato, essa postura é pouco usual, visto que a maioria dos pais não atua na redução do consumo de bebidas açucaradas:

"Meus pais sabem que não é saudável e até falam um pouco para não consumir, mas eles não estimulam para parar de fato de consumir" (EVIII).

Além dos pais, outra influência que se exerce sobre os adolescentes é a pressão dos amigos. Os entrevistados em período escolar reconhecem que passam muito mais tempo reunidos com os amigos do que com a família, tal situação faz com que compartilhem as opiniões sobre os hábitos alimentares ${ }^{25,43}$.

“...dificilmente quando saio com meus amigos alguém opta por pedir um suco natural, de certa forma impulsiona na decisão de optar por refrigerante.” (EX).

“...tomo mais refrigerante quando eu estou com meus amigos." (EIII).

Até mesmo os jovens que pouco consomem bebidas açucaradas em suas casas e em seu cotidiano afirmaram que ao sair com os amigos também aceitavam ingerir esse tipo de bebida, com vistas a evitar constrangimentos e exclusão da situação de divertimento.

"Várias vezes já sai com minhas amigas e acabei tomando refrigerante só porque elas estavam tomando e eu não quis ser diferente, mesmo sabendo que não ia ser uma boa escolha para mim. Quando eu escolho não tomar refrigerante, meus amigos acham estranho e brincam com isso, mas não é algo que me incomoda.” (EXI).

O entrevistado EV evidenciou a dificuldade que tem de parar de consumir bebidas açucaradas, apontando seus amigos:

“...meus amigos não me ajudam a não beber.” (EV).

O entrevistado EVI também relatou a dificuldade oriunda do convívio com os amigos e citou uma situação que para ele é irrecusável:

"No final de semana assim, os meninos aparecem e falam 'vamos tomar uma Coca-Cola gelada’... não dá para negar!!” (EVI).

Dessa forma, foi possível constatar que apesar da tentativa de alguns dos pais em estimularem uma nova consciência de consumo, suas ações atuam de modo contrário a seus discursos, o que impacta sobremaneira na conduta dos jovens quanto à redução do consumo de bebidas açucaradas. Entretanto, a influência dos pais se torna pequena quando comparada às influências geradas pelos amigos, de modo que todos os entrevistados assumiram que na presença de seus colegas não conseguem resistir e consomem algum tipo de bebida açucarada. 
A influência gerada na escola foi examinada como baixa devido à lei que proíbe a venda de refrigerantes nas escolas, fazendo com que os jovens ou consumam sucos naturais ou água. O consumo de refrigerantes se torna responsabilidade do aluno, na medida em que o refrigerante pode vir de outro contexto fora do controle da escola. Tais evidências corroboram a tese dos estudos de Pettigrew et al. ${ }^{27}$, que analisaram a influência gerada pelo assédio social, no qual os adolescentes consomem bebidas açucaradas para serem aceitos em seus grupos e situações e não se sentirem deslocados.

\section{Olhar saudável}

Na maioria das vezes, os adolescentes costumam consumir lanches e fast food ricos em calorias e sem grande valor nutricional. $\mathrm{Na}$ fase da adolescência, devido ao grande gasto calórico relacionado à fase de crescimento e de mudanças hormonais, muitos deles não conseguem vislumbrar o impacto na saúde desse tipo de alimentação, e por isso julgam como sendo pouco relevante se alimentar de forma saudável ou praticar exercícios físicos ${ }^{44}$.

Estudos apontam que consultar os rótulos das embalagens faz com que os consumidores façam escolhas melhores ao comparar produtos e suas especificações nutricionais ${ }^{45,46}$. Durante as entrevistas, foi possível identificar que aqueles jovens possuem pouco interesse em identificar as informações nutricionais dos alimentos que consomem, a maioria deles admitiu que não saberia verificar os elementos que são descritos nas informações nutricionais dos produtos industrializados.

\footnotetext{
"Eu nunca leio, sei o que faz mal, mas eu nunca leio... Nem sei identificar o que tem porque nunca tive interesse". (EVI).

"Nunca vejo essas informações nutricionais porque eu não sinto interesse. Eu não como muita coisa industrializada, por costume de casa, quando eu como eu nunca procuro as informações nem o que significam essas coisas”. (EXI).
}

Tais relatos indicam as dificuldades de interpretação enfrentadas pelos consumidores, que muitas vezes encontram poucas informações disponíveis nos produtos que adquirem, contribuindo para um baixo nível de letramento alimentar dos adolescentes e comprometendo a decisão de compra. Embora alguns dos entrevistados tenham demonstrado estar atentos para as informações nutricionais, há ainda as dificuldades relacionadas aos tipos de nutrientes disponíveis nos produtos.

"Olho não, mas sei como e quanto me prejudica algumas coisas. Mas eu não costumo comer biscoitos, refrigerantes... Sempre como o mais saudável é costume de casa”. (EII).

A entrevistada EX se tornou vegetariana há pouco mais de um ano e, além de expor sua busca pela compreensão da composição dos alimentos, evidencia que mudar seu hábito alimentar contribuiu para a criação de hábitos mais saudáveis em sua rotina:

"Desde que me tornei vegetariana procuro sempre ler os rótulos, pesquisar e compreender o que significam" (EX).

Os adolescentes ainda estão formando seus hábitos e não possuem tanta vontade de buscar comidas saudáveis que contribuam para uma melhoria de vida. Com o tempo, os jovens desenvolvem o interesse em se informar e buscar alimentos mais saudáveis mediante problemas de saúde, incluindo o aumento de peso e as alterações nos exames médicos. Essa mudança em seus hábitos faz ser necessária a busca por informações nutricionais nas embalagens dos produtos no processo de escolha alimentar. 


\section{Me atrai e é tão bom!}

Os hábitos gerados na infância contribuem para abertura a outros aspectos na adolescência que envolvem o consumo de bebidas açucaradas. Soma-se, também, a eficiência das ferramentas de marketing que aprimoram cada vez mais a atratividade do produto ${ }^{47}$. O principal aspecto de atratividade das bebidas açucaradas é o sabor diferenciado, mais doce, mais agradável e mais fácil de ser consumido. Assim, quando questionados sobre as razões que os levam a ingerir refrigerantes e outros tipos de bebidas, os entrevistados reforçaram o sabor e a conveniência (praticidade e preço baixo).

O sabor é considerado um fator que influencia diretamente na escolha alimentar. Não importa a situação do indivíduo, o sabor é o que irá levá-lo a desejar consumir determinado produto a fim de suprir, como já discutido, sua necessidade por meio de um alimento saboroso que produzirá prazer ao ser consumido ${ }^{16}$. Durante as entrevistas, todos os sujeitos corroboraram que é o sabor das bebidas açucaradas que os leva a consumi-las, já que muitas vezes são vistas como alimento diferente nas suas refeições normais e até certo ponto irrecusáveis. De tal forma que, as bebidas açucaradas assumem o patamar de produto que proporciona uma fuga da rotina imposta pelos familiares e proposta na escola:

\footnotetext{
"Só (consumo) porque é gostoso, falar a verdade... porque é bom demais!! Sério mesmo, não tem um motivo certo é porque é bom mesmo" (EV).

"Eu consumo pelo sabor, por sair da rotina de só tomar suco". (EI).

"Às vezes vai, tipo, se tiver um suco que eu goste, eu vou deixar o refrigerante para tomar suco. Mas se for um suco que eu não goste e o refrigerante tiver lá, vou optar pelo refrigerante" (EII).
}

A disponibilidade dos alimentos é um fator influenciador no consumo, e as bebidas açucaradas, por sua vez, ganham evidência ao serem expostas em locais de fácil acesso, com baixo preço e a praticidade do alimento pronto. Os depoimentos abaixo reforçam tal argumento.

\footnotetext{
"Pela praticidade... se chega num restaurante ou lanchonete, não precisa esperar... está lá, pronto! O motivo é apenas a praticidade mesmo já que acho um suco natural muito mais saboroso" (EX).

"O sabor e a comodidade porque você não tem o trabalho de fazer, em todo canto tem com preço baixo" (EVIII).

"Sabor, hábito... o costume é o que maltrata. E também pela facilidade. Chegar numa lanchonete, a pessoa vê o salgado lá e pede, ter que esperar um tempão por um suco é o que é péssimo. O refrigerante não, está lá, junto do salgado, não tem espera. E também, um suco de fruta normalmente custa 4 a uns 10 reais. Isso um copo. Com 6 reais dá para comprar 2 litros de Coca-Cola! É uma competição bem injusta... Sair com 4 amigos, mais fácil comprar uma Coca-Cola de 2 Litros por 6 reais do que cada um beber um suco de laranja a 6 reais cada copo". (EVII).
}

As empresas utilizam estratégias de marketing extremamente eficientes para fazer com que o adolescente prefira determinada bebida ${ }^{48,49}$. Estudos comprovam que quanto mais um indivíduo está exposto à publicidade de comidas fast food e bebidas, mais consome esses alimentos ${ }^{50,51}$. Nesse ímpeto, as empresas buscam criar uma identificação entre a marca e o consumidor, de forma que a necessidade de consumir o que está sendo oferecido, independentemente da necessidade e dos eventuais benefícios, seja reforçada ${ }^{52}$.

No geral, as bebidas açucaradas foram definidas como um alimento essencial na rotina dos entrevistados, uma vez que seu consumo é irrecusável e pouco repreendido entre os familiares, além de ser facilmente justificado pela praticidade do produto pronto e saboroso às mãos.

\section{Discussão dos resultados}

Esse tópico tem como propósito analisar de forma conjunta os resultados da pesquisa à luz da literatura de base. Assim, observa-se que, enquanto crianças, dois aspectos impulsionam a vontade de consumir bebidas açucaradas. O primeiro deles remete ao fato de que as refeições podem ocorrer em espaços que 
estimulam o consumo dessas bebidas, como shopping centers, restaurantes e lanchonetes. Em segundo lugar, os fatores que envolvem questões sociodemográficas e o nível de escolaridade, sendo o consumo mais elevado em famílias de menor grau de instrução e menor nível de renda familiar. Como visto no estudo, os sujeitos que costumam ir a eventos sociais ou sair com os amigos com maior frequência estão suscetíveis à pressão social dos amigos e da situação para o consumo de bebidas açucaradas.

Em verdade, as mães de classes sociais mais favorecidas restringem mais o consumo de bebidas açucaradas, na medida em que se preocupam com questões de saúde e acreditam que podem influenciar no gosto das crianças, enquanto as mães de baixa classe social, pela falta de informação, permitem o consumo desse produto com maior frequência ${ }^{30}$. Isso foi comprovado pela análise, na medida em que o excesso e a disponibilidade de bebidas açucaradas nos lares desencadearam uma preocupação que evoluiu para que toda a família deixasse de consumir. Neste sentido, também foi verificado que os adolescentes em fase escolar que moravam com os pais tinham rotinas alimentares mais saudáveis, com menos industrializados e mais controle sobre o que estava sendo consumido.

Concomitantemente, foi possível verificar que se os pais se restringem apenas a discursar sobre o quão prejudicial é o consumo de tais bebidas, mas ainda persistem em comprar e disponibilizar os produtos em suas casas, os adolescentes não assumem uma postura crítica com relação à alimentação. Enquanto isso, os jovens que já cursavam o ensino superior e estavam morando longe da família apresentavam maior nível de flexibilidade com relação às suas escolhas alimentares. De fato, a elevada flexibilidade no controle alimentar dos pais é um dos maiores influenciadores no consumo de bebidas açucaradas, pois os entrevistados que apresentaram maior capacidade reflexiva frente à pressão social são os que tiveram uma educação alimentar mais consciente ou que sofreram com problemas de saúde.

Apesar de todos demonstrarem boa formação de seus hábitos alimentares, o sabor, praticidade e o preço emergiram como fortes influenciadores no consumo de bebidas açucaradas. A priori, é preciso entender que o consumo excessivo de bebidas açucaradas, o hábito diário de assistir televisão por mais de três horas e a exposição à publicidade de alimentos estão diretamente associados, já que os refrigerantes e outras bebidas açucaradas não possuem regulação estatal acerca do limite para a exibição, e isso impacta sobremaneira no consumo dos adolescentes ${ }^{53}$. Além disso, é possível relatar que os aspectos relacionados ao alto nível de disponibilidade, aos diversos sabores, cores e aromas, e às dificuldades da vida cotidiana conduzem os adolescentes a escolherem com maior facilidade tais produtos.

Ademais, a maioria dos jovens se mostrou sem interesse nas informações calóricas dos alimentos que consomem. Os jovens que relataram buscar entendimento sobre essas informações foram os que mostraram possuir o hábito de consumir alimentos mais saudáveis e menos industrializados. Isso reforça o entendimento de que quanto maior for a disponibilidade de informações sobre o produto, mais o consumidor será capaz de julgar quais alimentos devem compor sua rotina alimentar. No entanto, para que isso ocorra é necessário refletir sobre novas formas de exposição das informações nutricionais dos alimentos.

Nesse ímpeto, a agenda global da prevenção e controle da obesidade infantil definiu como emergenciais e prioritárias as ações públicas e sociais com finalidade de gerar a diminuição do consumo de bebidas açucaradas. Tais medidas incluem ações de educação alimentar e nutricional que envolvem pais, familiares e cuidadores, o controle da indústria de alimentos com a regulação da publicidade de alimentos e uma política de taxação fiscal de bebidas açucaradas. No Brasil vem sendo discutido o aumento de impostos para refrigerantes, a fim de conter o avanço do consumo desse produto ${ }^{6}$. Discussão essa que também ocorreu no México, tendo como resultado a implantação de novas regras de taxação fiscal, o que resultou na redução da compra desses alimentos no varejo ${ }^{53}$.

Tais resultados podem indicar um caminho eficiente no que diz respeito à promoção de ações de marketing social para a redução do consumo de bebidas açucaradas. As organizações que atuam em causas relativas a crianças e adolescentes podem propor uma regulação tanto em termos de precificação, de 
veiculação de propagandas, como de educação nutricional. Por fim, os resultados evidenciam a necessidade de uma ação de divulgação dos malefícios do consumo de bebidas açucaradas no longo prazo.

\section{Considerações finais}

O objetivo principal deste estudo foi identificar as influências sobre o consumo de bebidas açucaradas por adolescentes. Observa-se pelos resultados que a influência para a redução se dá com a conscientização sobre os aspectos negativos do consumo, com a inserção de ações reguladoras e exposição dos malefícios para contribuir na diminuição do consumo, evidenciando a melhoria de vida ocasionada pelo consumo consciente dessas bebidas.

Nota-se que quando os adolescentes não consomem esses alimentos dentro de suas casas e possuem uma consciência desenvolvida a respeito dos malefícios desses produtos, há uma redução no consumo em geral. Com isso, acredita-se que este estudo contribui para um melhor entendimento sobre as influências de consumo de bebidas açucaradas por adolescentes. Por fim, consideram-se os resultados desta pesquisa condizentes com a realidade em que os adolescentes envolvidos estão inseridos, embora seja necessário desenvolver pesquisas que adotem outras abordagens, já que as influências para o consumo de bebidas açucaradas podem variar de acordo com regiões e realidades em que os adolescentes estejam inseridos. Assim, é recomendado que sejam realizados estudos considerando outras realidades, culturas, escolaridades, condição financeira e aspectos sociodemográficos.

\section{Referências}

1. Andreasen A. Social marketing: its definition and domain. J Public Policy Mark. 1994;13(1):108-14.

2. Kotler P, Lee NR. Marketing social: influenciando comportamentos para o bem. 3rd ed. Porto Alegre: Bookman; 2011.

3. Stead M, Hastings G, McDermott $L$. The meaning, effectiveness and future of social marketing. Obes Rev. 2007;8:189-93.

4. Burguete JLV. Pasado, presente y futuro de las dimensiones pública y social en el desarrollo conceptual del marketing. Rev Inter Mark Público No Lucr. 2004 jun;1:9-34.

5. Quaioti TCB, Almeida SS. Determinantes psico-biológicos do comportamento alimentar uma ênfase em fatores ambientais que contribuem para a obesidade. Psicologia USP. 2006;17(4):193-211.

6. Debate: taxação de refrigerante pode reduzir o consumo e evitar a obesidade? [Internet]. Estadão (Grupo OESP) 2017 jul. 17 [citado em 2017 set. 19]:Saúde. Disponível em: http://saude.estadao. com.br/noticias/geral, debate-taxacao-de-refrigerantes-pode-reduzir-o-consumo-e-evitar-aobesidade, 70001884892 .

7. World Health Organization. Diet nutrition and the prevention of chronic diseases, diet, nutrition and the prevention of chronic diseases [Internet]. Geneva: The Organization; 2014 [cited 2017 July 15]. Available from: https://apps.who.int/iris/bitstream/handle/10665/42665/WHO TRS 916.pdf;jsessionid= 6CFF3F6C66B85D475685E8C85CDAA748? sequence $=1$.

8. Bleil I. O padrão alimentar ocidental: considerações sobre a mudança de hábitos no Brasil. Cad Debate. 1998;VI:1-25.

9. Mendonça $\mathrm{CP}$, Anjos Ad. Aspectos das práticas alimentares e da atividade física como determinantes do crescimento do sobrepeso/obesidade no Brasil. Cad Saúde Pública. 2004 maio-jun;20(3):698-709.

10. Associação Brasileira das Indústrias de Refrigerantes e de Bebidas não alcoólicas [Internet]. Brasília: A Associação; 2015 [citado em 2016 abril 26]. Disponível em: https://abir.org.br/o-setor/bebidas/.

11. Araújo C. Saiba o que você está comendo: suco de caixinhas [Internet]. Brasília: PropagaNUT; 2013 [citado em 2016 set. 28. Disponível em: https://propaganut.wordpress.com/2013/05/13/saiba-o-quevoce-esta-comendo-sucos-de-caixinha/. 
12. Harris JL, Schwartz MB, Brownell KD. Sugary drink FACTS: Food Advertising to Children and teens score [Internet].; 2016 [cited 201609 28]. Available from: https://foodmyths.org/reports-resources/sugarydrinks-facts-food-advertising-to-children-and-teens-score/.

13. Ministério da Saúde (BR). Departamento de Análise de Situação em Saúde: plano de ações estratégicas para o enfrentamento das doenças crônicas não transmissíveis (DCNT) no Brasil. Brasília: O Ministério; 2011.

14. Horta M, Cardoso A, Lopes ACS, Santos Cd. Qualidade de vida entre mulheres com excesso de peso e doenças crônicas não transmissíveis. RGE. 2013;34(4):121-29.

15. Leal GVDS, Philippi S, Matsudo SMM, Toassa EC. Consumo alimentar e padrão de refeições de adolescentes, São Paulo, Brasil. Rev Bras Epidemiol. 2010;13(3):457-67.

16. Estima CCP, Philippi ST, Araki EL, Leal GVS, Martinez MF, Alvarenga MdS. Consumo de bebidas e refrigerantes por adolescentes de uma escola pública. Rev Paul Pediatr. 2011;29(1):41-45.

17. Sichieri R, Souza RAd. Estratégias para prevenção da obesidade em crianças e adolescentes. Cad Saúde Pública. 2008;24(suppl. 2):209-23.

18. Ministério da Saúde (BR). Incentivo à alimentação saudável. Brasília: O Ministério; 2016.

19. IBGEeduca [Internet]. Rio de Janeiro: IBGE; 2014 [citado em 2016 set. 30]. Disponível em: https:// educa.ibge.gov.br/.

20. Flora SR, Polenick CA. Effects of sugar consumption on human behavior and performance. Psychol Record. 2013 July:63(3):513-24.

21. Ludwing DS, Peterson KE, Gortmaker SL. Relation between consumption of sugar-sweetened drinks and childhood obesity: a prospective, observational analysis. Lancet. 2001 Feb;357(9255):505-8.

22. Kass N, Hecht K, Paul A, Birnbach K. Ethics and obesity prevention: ethical considerations in 3 approaches to reducing consumption of sugar-sweetened beverages. Am J Public Health. 2014 May;104(5):787-95

23. Jiménez-Cruz A, Gómez-Miranda LM, Bacardí-Gascón M. Estudios aleatorizados sobre el efecto del consumo de bebidas azucaradas sobre la adiposidad en menores de 16 años; revisón sistemática. Nutr Hosp. 2013;28(3):1797-1801.

24. Pollard CM, Meng X, Hendrie GA, Hendrie D, Sullivan D, Pratt IS et al. Obesity, socio-demographic and attitudinal factors associated with sugar-sweetened beverage consumption: Australian evidence. Aust $\mathrm{N}$ Z J Public Health. 2016 Feb;40(1):71-7.

25. Verstraeten R, Leroy JL, Pieniak Z, Avilès AO, Holdsworth M, Verbeke W et al. Individual and environmental factors influencing adolescents' dietary behavior in low-and middle-income settings. PLoS One. 2016 Jul 22;11(7):e0157744.

26. Bleakley A, Jordan AB, Hennessy M, Glanz K, Strasser A, Vaala S. Do Emotional Appeals in Public Service Advertisements Influence Adolescents' Intention to Reduce Consumption of Sugar-Sweetened Beverages. J Health Commun. 2015 Aug;20(8):938-48.

27. Pettigrew S, Jongenelis M, Chapman K, Miller C. Factors influencing the frequency of children's consumption of soft drinks. Appetite. 2015 Aug;91:393-8.

28. Grimm C, Harnack L, Story M. Factors associated with soft drink consumption in school-aged children. J Am Diet Assoc. 2004 Aug;104(8):1244-9.

29. Malta DC, Machado IE, Porto L, Silva MMAd, Freitas PCd, Costa AWNd, et al. Consumo de álcool entre adolescentes brasileiros segundo a Pesquisa Nacional de Saúde Escolar (PeNSE 2012). Rev Bras Epidemiol Suppl PeNSE. 2014;203-14.

30. Carvalho HIM. Percepções relativamente às bebidas açucaradas. Um contributo para compreender o consumo de refrigerantes em crianças [dissertação]. Porto: Universidade do Porto; 2014.

31. Bastos AdFV, Costa JFd, Vasconcelos MM. Consumo de bebidas alcoólicas por jovens: implicações para o marketing social. ReMark. 2017 out./dez;16(4):469-86.

32. Hawkes C. Marketing food to children: the global regulatory environment. Brasília: Organização Mundial da Saúde; Organização Pan-Americana da Saúde; Agência Nacional de Vigilância Sanitária; 2006.

33. Bachman CM, Baranowski T, Nicklas TA. Is there an association between sweetened beverages and adiposity? Nutr Rev. 2006 Apr;64(4):153-74. 
34. Broeiro P. Promoção de saúde e marketing social. Rev Port Med Geral Fam. 2015 fev.;31(1):6-9.

35. Leitão LCA, Simões MOdS, França ISXd. A saúde pública e a indústria farmacêutica: implicações bioéticas na produção do cuidado. 2012 out. Rev Bras Ciênc Saúde;16(3):295-302.

36. Vega JB, Poblacion AP, Taddei JAdAC. Fatores associados ao consumo de bebidas açucaradas entre préescolares brasileiros: inquérito nacional de 2006. Ciênc Saúde Coletiva [Internet]. 2015 [citado em 2019 jun. 07];20(8):2371-80. Disponível em: https://bit.ly/2WrPnw1.

37. Bleakley A, Jordan AB, Hennessy M, Glanz K, Strasser A, Vaala S. Do Emotional Appeals in Public Service Advertisements Influence Adolescents' Intention to Reduce Consumption of Sugar-Sweetened Beverages. J Health Commun. 2015 Aug;20(8):938-48.

38. Barboza IS. Marketing social aplicado à doação de sangue: fatores condicionantes de comportamento. Cad Saúde Pública. 2014;30(7):1463-74.

39. Merriam S. Qualitative research: a guide to design and implementation. São Francisco, CA: Jossey-Bass; 2009.

40. Bardin L. Análise de conteúdo. Lisboa: Edições 70; 2007.

41. Abrantes MM, Lamounier JA, Colosimo A. Prevalência de sobrepeso e obesidade em crianças e adolescentes das regiões Sudeste e Nordeste. J Pediatr. 2002 maio;78(4):335-40.

42. Toral N, Conti MA, Slater. A alimentação saudável na ótica dos adolescentes: percepções e barreiras à implementação e características esperadas em materiais educativos. Cad Saúde Pública. 2009;25(11):2386-94.

43. Bruschini MCA. Mulher, casa e família: cotidiano nas camadas médias paulistanas. São Paulo: Fundação Carlos Chagas; Vértice; 1990.

44. case of sugar-sweetened beverage sales in schools. Am J Public Health. 2008 Apr;98(4):595:604.

45. Carvalho CMRG, Nogueira AMT, Teles JBM, Paz SMR, Sousa RMLd. Consumo alimentar de adolescentes matriculados em um colégio particular de Teresina, Piauí, Brasil. Rev Nutri. 2001 maio/ago.;14(2):85-93.

46. Santos LAdS. Educação alimentar e nutricional no contexto da promoção de práticas alimentares saudáveis. Rev Nutr Campinas. 2005 set./out.;18:681-92.

47. Monteiro RA, Coutinho JG, Recine E. Consulta aos rótulos de alimentos e bebidas por frequentadores de supermercados em Brasília, Brasil. Rev Panam Salud Publica. 2005;18(3):172-77.

48. Silva BFC, Lu Yang DD, Costa EL. A influência das estratégias de marketing no processo de decisão de compra dos consumidores jovens nos mercados de cerveja e refrigerantes. Jovens Pesquis Mackenzie. 2007 jan./jun.; 4(1):1-20.

49. Malik VS, Willet WC, Hu FB. Global obesity: trends, risk factors and policy implications. Nat Rev Endocrinol. 2013 Jan;9(1):13-27.

50. Popkin BM. Sugary beverages represent a threat to global health. Trends Endocrinol Metabolism. 2012 Dec.;23(12):591-93.

51. Andreyeva T, Kelly R, Harris JL. Exposure to food advertising on televison: associations with children's fast food and soft drink consumption and obesity. Econ Hum Biol. 2011 Jul;9(3):221-33.

52. Carvalho MD. Os padrões de consumo de bebidas açucaradas das crianças da lousã e sua relação com o índice de massa corporal [dissertação]. Coimbra: Universidade de Coimbra; 2013.

53. Pereira RCF, Almeida O, Notti FL. Marketing de gerações: construção e teste de escala para avaliação da marca de refrigerante Coca-Cola por jovens na fase de transição entre as gerações X e Y. REAd. 2006 jul.-ago.;12(4):102-26.

54. Jaime PC, Prado Rd, Malta DC. Influência familiar no consumo de bebidas açucaradas em crianças menores de dois anos. Rev. Saúde Pública. 2017 jan.;(51 Supl):1s-10s.

55. Kotler $P$, Zaltman. Social marketing: an approach to planned social change. J Marketing. 1971 July;35(3):3-12.

56. Carmo MB, Toral N, Silva MV, Slater B. Consumo de doces, refrigerantes e bebidas com adição de açúcar entre adolescentes da rede pública de ensino de Piracibaca, São Paulo. Rev Bras Epidemiol. 2006;9(1):121-30. 